\title{
Androgens in relation to prenatal development and postnatal inversion of the gubernacula in rats
}

\author{
P. van der Schoot \\ Department of Endocrinology and Reproduction, Faculty of Medicine and Health Sciences, \\ Erasmus University, PO Box 1738, 3000 DR Rotterdam, Netherlands
}

\begin{abstract}
Summary. Exposure of male rats to the anti-androgen flutamide during fetal life, from day 10 after conception to the day of birth, allowed quantitatively unaltered development of the gubernacula. Apparently, androgens play no important role or no role at all in their growth.

Castration of newborn male rats did not interfere with the inversion during further postnatal life of the gubernacula to create the muscular parts of the scrotum (cremaster muscles). Prenatal exposure to flutamide, followed by castration immediately after birth, also allowed gubernacular inversion and cremaster muscle growth. Neonatal administration of testosterone, after castration at birth, did not enhance gubernacular inversion or promote cremaster muscle growth in infancy or during adulthood. Apparently, postnatal gubernacular inversion and cremaster muscle growth are independent not only of androgens, but also of all testis hormones.

Neonatal administration of the potent androgen $5 a$-dihydrotestosterone propionate suppressed gonadotrophin secretion and, in intact males, inhibited testicular growth. Administration from the day of birth to day 33 delayed testicular descent and enhanced growth of the genital apparatus, but did not affect the size of the cremaster muscles.

These experiments indicate that androgens are not involved in the processes that create the cavities into which testes descend to acquire their full reproductive potential.
\end{abstract}

Keywords: gubernacula; cremaster muscles; flutamide; testicular growth; rat

\section{Introduction}

Testicular descent is part of sexual differentiation. Ovarian descent does not occur and the scrotal cavities (cremaster muscle sacs), into which testes are to descend, are present in males only. The processes underlying this sex difference are unknown, but there is a wide belief that testicular androgens play a role (Hamilton, 1938; Elder et al., 1982; for review see Hutson \& Donahue, 1986; George \& Peterson, 1988; Husmann \& McPhaul, 1991). This view is based mainly on reported or supposed effects of androgen (either given by direct administration or, indirectly, secreted in response to exogenous gonadotrophin or luteinizing-hormone-releasing hormone) to promote testicular descent in cryptorchidism (for review see Habenicht \& Neumann, 1983).

Testicular androgens as the supposed agents of the stabilization and postnatal development of the cremaster muscle anlagen are difficult to reconcile with at least two groups of data. First, the human and animal syndrome of androgen insensitivity (also called testicular feminization syndrome) is frequently reported to be associated with the occurrence of inguinal hernia sacs with or without testes contained within them (man: Polani, 1962, 1970; Campbell, 1970; rat: Rosenfield et al., 1971; Stanley et al., 1973; mouse: Hutson, 1986; pig: Wensing \& Colenbrander, 1986; dog: Fentener van Vlissingen et al., 1988). Second, prenatal exposure of human female fetuses to androgens, as part of the syndrome of congenital adrenal hyperplasia, is reported not to be associated 
with inguinal hernia sac formation (Jones \& Klingensmith, 1985; Scheffer et al., 1988). These data indicate that cremaster muscle sacs develop in the absence of androgen action and that abnormal exposure to androgens during fetal life is not sufficient for later cremaster sac growth. The otherwise 'feminine' external genital development in testicular feminization, on the one hand, and their 'masculine' development in congenital adrenal hyperplasia, on the other, unequivocally demonstrate the absence and presence, respectively, of 'organizational' androgen action on the developing genitalia anlagen.

The cremaster muscles of the scrotum in rats develop from papilla-like gubernacula (or inguinal cones: Raynaud, 1958) which protrude from the bottom of the abdomen in male animals during the last days of their prenatal life (Bergh et al., 1978; Beasley \& Hutson, 1988). The epididymides and testes are connected to the tip of these structures with small ligaments. Around birth, inversion of the papilla-like gubernacula starts: from a papilla there soon develops a muscular canal extruding caudally from the abdominal cavity. The point of attachment of the ligaments becomes the bottom of this muscular canal. As this canal grows, first the epididymis and then the testis become contained within it and descend. The precise mechanism of descent has not yet been elucidated and hormonal as well as non-hormonal mechanisms (mechanical action of intra-abdominal pressure: Bergh et al., 1978; Frey et al., 1983) are considered to be involved.

The present experiments were undertaken to clarify further the possible role of androgens in (1) the prenatal growth and development of the inguinal cones of the gubernacula and (2) the perinatal inversion and postnatal outgrowth of these inguinal cones to become the cremaster muscle sacs. Prenatal growth was studied in rats exposed, or not, to an anti-androgen during their prenatal life. Postnatal inversion and further growth was studied after castration at birth, combined, or not, with prenatal exposure to the anti-androgen. Postnatal effects of androgens were studied by treating intact rats with the potent androgen $5 \alpha$-dihydrotestosterone propionate (DHTP) throughout infancy.

\section{Materials and Methods}

\section{Animals}

The experiments were performed with Wistar rats obtained from the breeding colony of TNO (Rijswijk, Netherlands) and with Sprague-Dawley rats obtained from Harlan Sprague-Dawley (Madison, WI, USA). Male and female animals were caged together and daily vaginal smears were taken to detect copulatory plugs. The day on which plugs were found was taken as day 0 of pregnancy. Usually, animals give birth on day 22. Pregnant females were injected daily and subcutaneously (s.c.) from day 10 of pregnancy with $10 \mathrm{mg}$ flutamide (SCH 13521, 4-nitro-3trifluoromethyl-isobutyranilide, Schering Ltd, Bloomfield, NJ, USA) in $0.1 \mathrm{ml} \mathrm{l,2-propanediol} \mathrm{(propyleneglycol)} \mathrm{or}$ propyleneglycol only. These treatments reportedly do not alter the duration of pregnancy (Neri et al., 1972). Injections were given between $08: 00$ and 10:00 h until litters were found. Hence, most pregnant animals were injected for the last time early on the day of parturition.

The dose of flutamide chosen was just below the maximum that animals would accept without developing health problems through the injections. The start on day 10 was chosen to guarantee exposure of fetuses to the anti-androgen continuously from well before the start of androgen-dependent sexual differentiation of the genitalia.

Animals were kept in standard conditions: they had free access to pelleted food (Hope Farms standard laboratory diet, Woerden, Netherlands) and tap water; temperature in the animal room was $20-22^{\circ} \mathrm{C}$; lights were on between 05:00 and 19:00 h.

\section{Exposure to flutamide and the development of the gubernaculum before birth}

Pregnant rats were killed by cervical dislocation on day 19 or 20 of pregnancy. Groups were composed of the offspring from at least two females. Male fetuses were dissected and the abdomen with attached lower extremities was fixed in Bouin's solution. After 2 days, the extremities and tail were cut off and the intestines were removed. The remaining part was processed for histological examination.

In the offspring of flutamide-treated animals no distinction between males and females could be made. The lower half of the body of each animal was fixed in Bouin's solution. After 2 days, the lower extremities, tail and intestines were removed. Inspection of the lower abdomen and the region caudal to the kidneys then allowed unequivocal distinction between females (with ovaries close to the caudal pole of the kidney; salpinx and uterine horn adjacent to the ovaries) and males (with testes in the area below the kidney and bladder). This procedure was chosen to prevent 
organ displacement through inspection of the abdomen before fixation and to avoid further histological examination of females.

Newborn animals were treated in a similar way. In addition, three control females and two flutamide-treated females were fixed for examination of their lower abdominal histology.

From the above procedure, lower body halves were obtained from control and flutamide-treated males on day 19 , 20 or 22 (day of birth) and from newborn females of the two groups.

All specimens were embedded in paraffin wax and parasagittal sections $0.01 \mathrm{~mm}$ thick were mounted serially to allow the evaluation of the structures and organs in the whole lower abdomen and of the internal and external genital apparatus including the gubernaculum.

\section{Gubernacular inversion after castration at birth}

Newborn males, exposed or not to flutamide prenatally, were castrated under cold anaesthesia (Pfeiffer, 1936). Castration took place at $0-2 \mathrm{~h}$ after birth to avoid effects on androgen-dependent developmental processes through the sudden rise of testicular testosterone secretion during the first hours after birth (Corbier et al., 1978). The animals were either left untreated on subsequent days or injected s.c. with testosterone propionate $(0.1 \mathrm{mg} \mathrm{TP})$ or olive oil solvent $(0.1 \mathrm{ml})$ on days 1,3 and 5 . The animals were killed on day 7 under cold anaesthesia. The lower abdomen was excised and fixed in Bouin's solution. Parasagittal paraffin sections were mounted 1:10 and the sections were examined for the presence and development of an inverted gubernaculum.

Other rats with a similar treatment in infancy were killed at later ages to establish the subsequent development of the inverted gubernacula by recording the weight of the cremaster muscle sacs. During the weeks before death, animals were injected daily with oil or $0.1 \mathrm{mg}$ TP in oil.

\section{Neonatal treatment with DHTP and outgrowth of the cremaster muscles}

Newborn males were injected with $0.1 \mathrm{mg}$ DHTP (Steraloids, Hamilton, NH, USA) in oil every other day from day I to day 33. Control animals received olive oil only. Half the animals were killed on day 35; the remaining animals were killed on day 145. At autopsy, the various androgen-dependent organs were weighed as well as the cremaster muscle sacs.

The effect of DHTP on the hypothalamo-hypophyseal-testis axis in neonatal males was evaluated in neonatally castrated rats. The animals were treated with DHTP or oil only on days 1, 3, 5 and 7 and killed on day 9. As controls, oil-treated intact animals were investigated. The penis was weighed at autopsy as an index of androgen action. The blood concentrations of gonadotrophins were measured as an index of pituitary function. Blood was obtained by puncturing the ophthalmic plexus under ether anaesthesia. The concentrations of luteinizing hormone and folliclestimulating hormone were measured in serum with radioimmunoassay techniques (Welschen et al., 1975) and expressed as $\mathrm{ng} \mathrm{ml}^{-1}$ of the respective RAT RPI standards.

\section{Statistical analysis}

Statistical evaluation of the experimental results comprised parametric two-sample comparisons using Student's $t$ test; parametric multiple-sample comparisons using one-way ANOVA and further evaluation of statistically significant differences with Tukey's honestly significant difference test (Kirk, 1968); nonparametric Fisher's exact test; or $\chi^{2}$ tests (Siegel, 1956). In all experiments, $P=0.05$ was adopted as the upper limit for statistical significance of the observed differences between groups.

\section{Results}

\section{Exposure to flutamide and the development of the gubernaculum before birth}

On days 19 and 20 after conception, the control males and those exposed to flutamide showed easily identifiable gubernacula in the lower abdomen (Fig. 1a, b). Measuring the number of serially mounted sections in which the organs were visible showed no significant difference in the diameter of the organs between the two groups. Testis size was also not significantly different (Table 1). Animals killed immediately after birth showed differences in the gubernacula, but not in testis size, between the two groups. Qualitatively, all five control animals showed signs of the initiation of gubernacular inversion (Fig. 2a). None of the rats exposed to flutamide showed signs of the start of gubernacular inversion (Fig. 2b); in contrast these structures had increased in height and diameter over the previous 2 days (Table 1 ). 
(a)

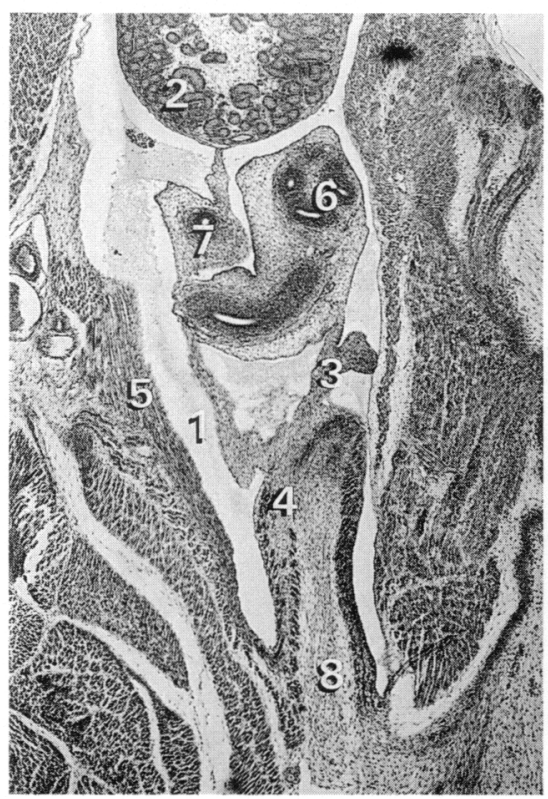

(b)

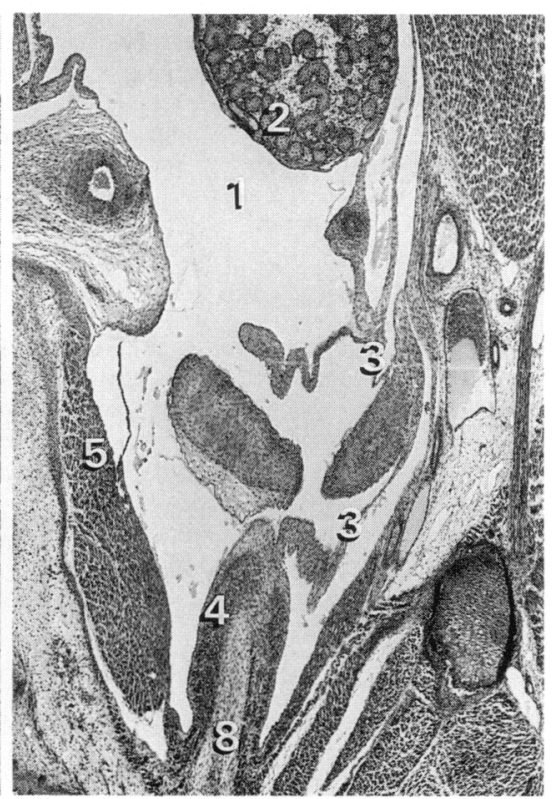

Fig. 1. Gubernaculum testis on day 19 after conception in (a) a normal male rat and (b) a male rat exposed to flutamide from day 10 after conception; $\times 28$. The lower abdomen has been cut parasagittally. The following structures can be distinguished: (1) abdominal cavity, (2) testis, (3) gubernacular cord, (4) gubernaculum proper (or inguinal cone), (5) ventral abdominal wall muscles, (6) caudal epididymis, (7) deferent duct and (8) mesenchymatous core of the gubernaculum. In (b) the gubernacular cord (3) is elongated compared with (a) and the caudal epididymis is absent.

Table 1. Diameter of testes and gubernaculum ( $\mu \mathrm{m} \pm \mathrm{SEM} ; 8-12$ observations per group) during the last days of prenatal life in rats exposed or not to flutamide from day 10 after their conception (on day 0 )

\begin{tabular}{llrrc}
\hline $\begin{array}{l}\text { Day after } \\
\text { conception }\end{array}$ & & Control & $\begin{array}{c}\text { Exposed to } \\
\text { flutamide }\end{array}$ & $\begin{array}{c}P \\
\text { (ANOVA) }\end{array}$ \\
\hline 19 & Testes & $970 \pm 60$ & $985 \pm 20$ & $-\dagger$ \\
& Gubernaculum & $510 \pm 40$ & $495 \pm 15$ & - \\
20 & Testes & $1165 \pm 90$ & $1120 \pm 70$ & - \\
\multirow{2}{*}{22 (birth) } & Gubernaculum & $600 \pm 105$ & $500 \pm 35$ & - \\
& Testes & $1260 \pm 70$ & $1285 \pm 35$ & - \\
& Gubernaculum & ${ }^{*}$ & $720 \pm 45$ & \\
\hline
\end{tabular}

*Not determined: in view of the start of gubernacular inversion (see Fig. 2a), no diameter measurement could be provided comparable to the measurements on previous days.

$\doteqdot P>0.05$.

Further histological examination revealed the expected masculine differentiation of the internal genitalia and urogenital sinus in the control animals. The muscular apparatus at the base of the penis was clearly identifiable as well as the bulbo-urethral glands and the penile urethra. Flutamide- 
(a)

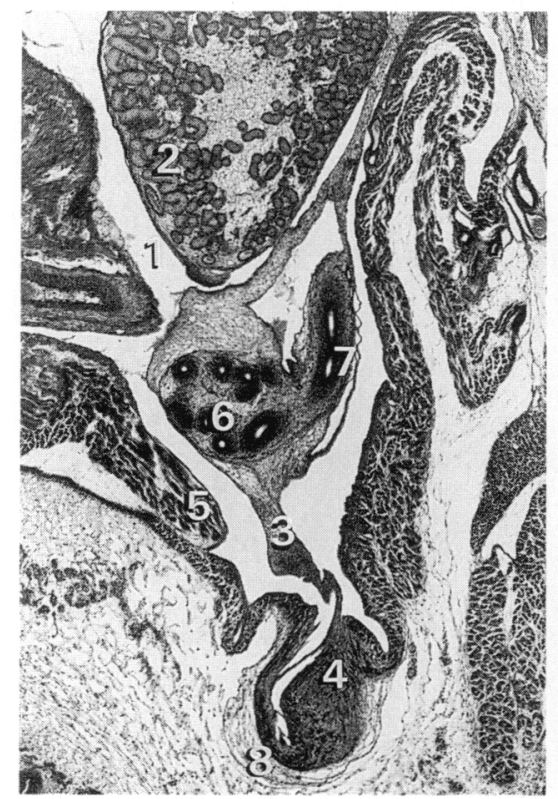

(b)

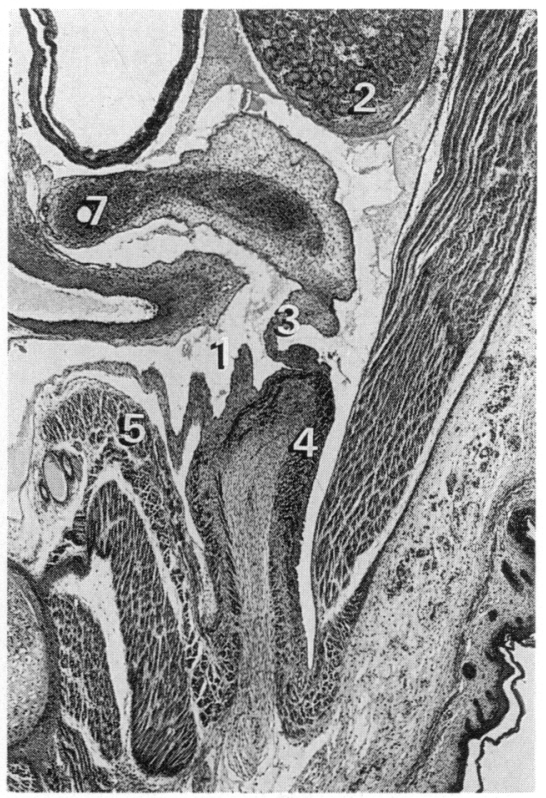

Fig. 2. The gubernaculum testis on day 22 after conception (day of birth) in (a) a normal male rat and (b) a male rat exposed to flutamide from day 10 after conception; $\times 28$. The gubernaculum (4) in (a) has started its inversion and the gubernacular mesenchymatous core (8) becomes transformed into a mesenchymatous sheath of the inverted gubernaculum. In (b) the gubernaculum (4) still projects into the abdominal lumen. See legend to Fig. 1 for key to other structures.

exposed males showed minor, but variable, development of the epididymis and seminal vesicles and no development of the prostate and muscular apparatus or bulbo-urethral glands at the base of the penis; all of them showed a clitoral urethra. Nipples were present in the ventral skin together with mammary duct anlagen (Fig. 3). The sagittal sinus had differentiated to a short vagina. In the control and flutamide-exposed rats, the testicular vasculature had the appearance known as plexus pampiniformis.

Female rats showed a minor structure in the lower abdomen similar to the male gubernaculum (Fig. 4). The female gubernacula extended dorsally to end as a minor piece of fat tissue. Medially, they ended in a minor ligament.

\section{Gubernacular inversion after castration at birth}

Neonatal castration allowed gubernacular inversion during the post-operative period (Table 2; Fig. 5). Prenatal exposure to flutamide did not seem to affect inversion after neonatal castration. Neonatal treatment with TP did not stimulate gubernacular inversion.

Although no specific techniques were used to establish cremaster muscle growth, it seems clear that the amount of muscular tissue of the inverted gubernaculum on day 7 of life exceeded the amount of muscular tissue in the gubernaculum at birth (Fig. 5, cf. Fig. 2a, b).

Examination at later ages revealed growth of cremaster sacs in neonatally castrated male rats. Only sacs that were identifiable as such were included in the measurement (Fig. 6). Intestines did not invade these 'inguinal herniae'. Treatment with TP in infancy or in adulthood did not seem to affect cremaster muscle size (Table 3). 


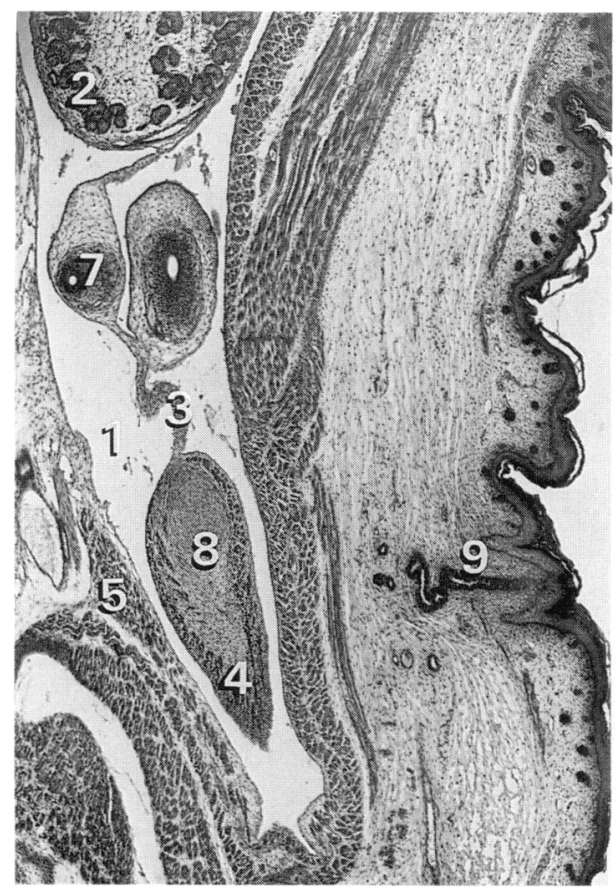

Fig. 3. The presence of a nipple and mammary duct canal (9) together with a well-developed gubernaculum $(4,8)$ in a newborn male rat exposed to flutamide during prenatal life; $\times 28$. See legend to Fig. 1 for key to other structures.

\section{Neonatal treatment with DHTP and outgrowth of the cremaster muscles}

Neonatal treatment with DHTP suppressed gonadotrophin secretion in neonatally castrated rats and induced penile growth (Table 4). In intact rats, the treatment suppressed testicular growth to a considerable degree (Table 5). The treatment significantly retarded the passage of the slowly growing testes through the inguinal canal. Testes had reached their intrascrotal position in all ten control rats by day 22 , but in eight of ten experimental rats the passage of the testes through the inguinal canal into the scrotal sacs had not occurred by day 30 . In contrast, epididymal descent into the scrotal sac had occurred in all rats of both groups on day 15. The androgen target organs of DHTP-treated rats had increased in weight beyond those of controls that were exposed only to endogenous testicular androgens. The cremaster muscles of DHTP-treated rats had not grown beyond the size of control animals on day 35. An estimation, at that age, of the weight of the whole cremaster sac contents (i.e. testis + epididymis + epididymis fat pad) revealed that these contents were not significantly different between the two groups (mean \pm SEM $463 \pm 44 \mathrm{mg}$ in control group and $446 \pm 29 \mathrm{mg}$ in DHTP-treated group, $P>0.2$ ).

Neonatal suppression of gonadotrophin secretion with large doses of androgen in general and DHTP specifically (Wilson \& Wilson, 1943; Feigelson, 1986) results in hypogonadotrophic hypogonadism during adulthood. Accordingly, at autopsy on day 145, testes and androgen-dependent organs remained small in DHTP-treated animals compared with controls (Table 5). The weight difference in cremaster muscles paralleled the weight difference in the whole of the cremaster sac contents $(5662 \pm 165 \mathrm{mg}$ in control rats and $4640 \pm 228 \mathrm{mg}$ in DHTP-treated rats, $P<0.01)$.

\section{Discussion}

Little unanimity exists in the literature with regard to the nomenclature of the gubernaculum and adjacent structures. The connection, during fetal life, between the testis-epididymis complex and 


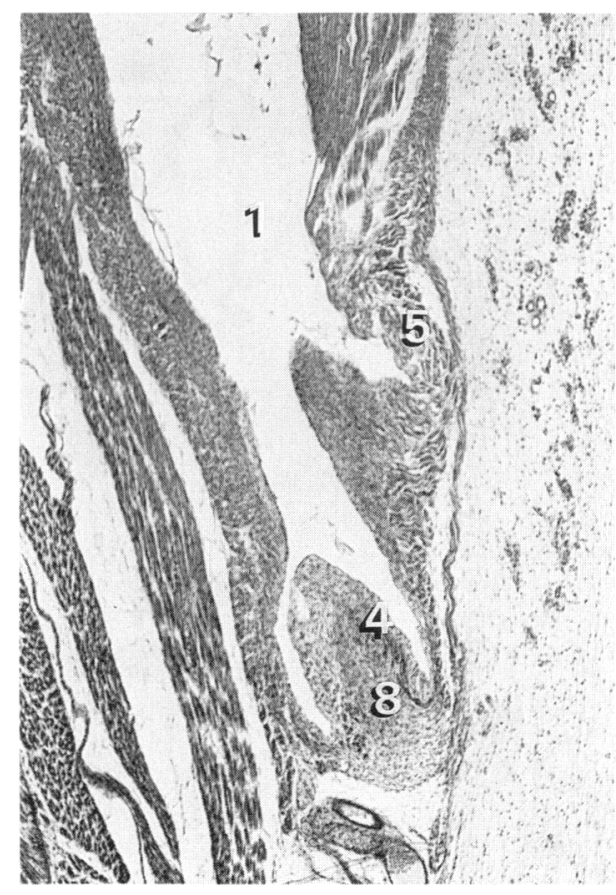

Fig. 4. The gubernaculum of a newborn female exposed to flutamide during prenatal life. The small papilla shows a similar structure to the large male gubernaculum (see Figs 1 and 2), and, accordingly, an outer muscular layer (4) and inner mesenchymatous core (8) can be unequivocally distinguished; $\times 56$.

Table 2. Gubernacular inversion on day 7 of life after castration of male rats on the day of birth (day 1)

\begin{tabular}{|c|c|c|}
\hline \multirow[b]{2}{*}{$\begin{array}{l}\text { Before } \\
\text { birth }\end{array}$} & Treatment & \multirow[b]{2}{*}{$\begin{array}{c}\text { Inversion } \\
>50 \%\end{array}$} \\
\hline & $\begin{array}{l}\text { After } \\
\text { castration }\end{array}$ & \\
\hline- & No treatment & 6 of 8 \\
\hline - & Oil on days 1,3 and 5 & 7 of 8 \\
\hline - & $\begin{array}{l}\text { Testosterone propionate } \\
(0 \cdot 1 \mathrm{mg}) \text { on days } 1,3 \text { and } 5\end{array}$ & 6 of 10 \\
\hline Flutamide & Oil on days 1,3 and 5 & 10 of 10 \\
\hline
\end{tabular}

the bottom of the abdomen consists of two parts: a mesenteric fold or 'ligament' and a 'bulb'. Occasionally, the ligament in isolation is called the 'gubernaculum' and the bulb is described as the 'inguinal cone' and considered to be a different organ (Starck, 1965; Habenicht \& Neumann, 1983; Newton \& Hamill, 1989). Accordingly, the term gubernaculum is also applied to the ligament between the testis and the bottom of the cremaster sac in adult animals (Hamilton et al., 1962). This definition of 'gubernaculum' represents a minority view. Most authors consider the 'gubernaculum' as a structure consisting of two parts: Wensing (1986) is among the proponents of the view to distinguish between the fetal 'gubernacular cord' (equivalent to the above ligament) and the 'intra-abdominal gubernacular segment' (equivalent to the inguinal cone; Bergh et al., 1978; 


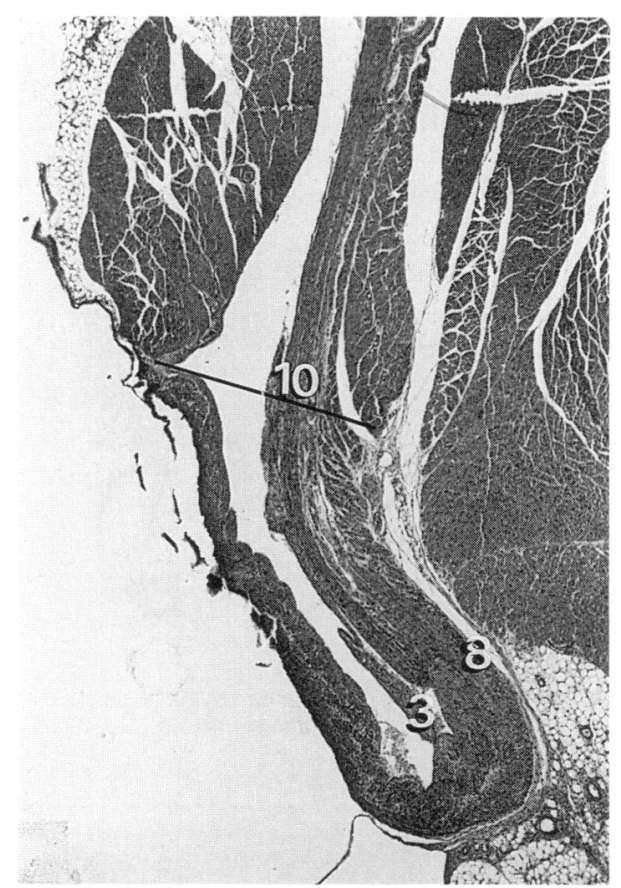

Fig. 5. The inverted gubernaculum on day 7 of life after castration on the day of birth of a normal male rat; $\times 28$. The inverted muscular part of the gubernaculum has now become the cremaster muscle sac. The muscular tissue is surrounded by the tissue which made up the mesenchymatous core of the gubernaculum. A remnant of the gubernacular cord (3) is attached to the bottom of the cremaster muscle sac. The line marked with (10) indicates the level of the lowest part of the gubernaculum before the birth (see Fig. 1). See legend to Fig. 1 for key to other structures.

Table 3. Weight of the cremaster muscle sac ( $\mathrm{mg} \pm$ SEM) in neonatally castrated rats treated or not with oil or testosterone propionate (TP) on days $1,3,5,7$ and 9 and killed at various later ages

\begin{tabular}{lccc}
\hline $\begin{array}{l}\text { Treatment } \\
\text { in infancy }\end{array}$ & $\begin{array}{c}\text { Treatment } \\
\text { before autopsy }\end{array}$ & $\begin{array}{c}\text { Cremaster } \\
\text { muscle sac } \\
(\mathrm{mg})\end{array}$ & $\begin{array}{c}P \\
\text { Student } t\end{array}$ \\
\hline Oil & $-^{*}$ & $13 \pm 4(n=7)$ & \\
Oil & $-^{\dagger}$ & $43 \pm 6(n=11)$ & $>0 \cdot 2$ \\
Oil & TP & $54 \pm 8(n=9)$ & $>0 \cdot 2$ \\
Oil & TP+ & $72 \pm 12(n=8)$ & 0.08 \\
TP & TP & $108 \pm 13(n=12)$ & 0.08 \\
\hline
\end{tabular}

*Age at autopsy, 33 days.

†Treatment with oil or TP from day 33, autopsy at age 55 days. $\mp$ Treatment from day 260 , autopsy at age 300 days.

Radhakrishnan et al., 1979; Beasley \& Hutson, 1988). The shape of the gubernaculum in perinatal rabbits does not allow the distinction between two separate parts, and the identity of the gubernaculum and the inguinal cone seems justified in view of the published drawings of these structures (Elder et al., 1982). 
Table 4. Effect in neonatally castrated (NC) male rats of $5 \alpha-$ dihydrotestosterone propionate (DHTP, $0 \cdot 1 \mathrm{mg}$ on days $1,3,5,7$ ) on the mean \pm SEM penile weight and the blood concentrations of hormones on day 9

\begin{tabular}{lccr}
\hline & $\begin{array}{c}\text { Luteinizing } \\
\text { hormone } \\
\left(\mathrm{ng} \mathrm{ml}^{-1}\right)\end{array}$ & $\begin{array}{c}\text { Follicle-stimulating } \\
\text { hormone } \\
\left(\mathrm{ng} \mathrm{ml}^{-1}\right)\end{array}$ & $\begin{array}{c}\text { Penis } \\
(\mathrm{mg})\end{array}$ \\
\hline Intact + oil & $43 \pm 7$ & $450 \pm 30$ & $14 \pm 1$ \\
NC + oil & $238 \pm 50$ & $2350 \pm 130$ & $7 \pm 1$ \\
NC + DHTP & $<30$ & $103 \pm 14$ & $22 \pm 3$ \\
Statistics & $*$ & \pm & + \\
\hline
\end{tabular}

Comparison of these variables with those obtained in intact 9-day-old male rats; $6-12$ observations per group.

*One-way anova $F(11,1)=17 ; P<0.01$.

tOne-way ANOVA $F(17,2)$ and $(35,2)$ respectively $>30 ; P \ll 0.001$.

Table 5. Gonadal, genital and cremaster muscle development in intact male rats treated with $5 \alpha$-dihydrotestosterone propionate (DHTP) during infancy ( $0 \cdot 1 \mathrm{mg}$ every other day from the day of birth until day $33 ; \mathrm{mg} \pm \mathrm{SEM} ; 4-6$ rats per group)

\begin{tabular}{|c|c|c|c|c|c|c|}
\hline & Testis & Epididymis & Penis & $\begin{array}{c}\text { Epididymal } \\
\text { fat }\end{array}$ & $\begin{array}{l}\text { Seminal } \\
\text { vesicles }\end{array}$ & $\begin{array}{l}\text { Musculus } \\
\text { cremaster }\end{array}$ \\
\hline \multicolumn{7}{|l|}{ Age 35 days } \\
\hline Control & $299 \pm 42$ & $31 \pm 4$ & $60 \pm 7$ & $133 \pm$ & $14 \pm 4$ & $50 \pm 6$ \\
\hline DHTP & $23 \pm 2$ & $78 \pm 4$ & $141 \pm 7$ & $345 \pm 29$ & $91 \pm 8$ & $57 \pm 4$ \\
\hline Student $t$ & $* * *$ & $* * *$ & $* * *$ & $* * *$ & $* * *$ & 0 \\
\hline \multicolumn{7}{|l|}{ Age 145 days } \\
\hline Control & $1645 \pm 5$ & $522 \pm 3$ & $240 \pm 2$ & $3495 \pm 166$ & $210 \pm 2$ & $513 \pm 3$ \\
\hline DHTP & $1014 \pm 33$ & $329 \pm 11$ & $218 \pm 3$ & $3297 \pm 188$ & $115 \pm 7$ & $364 \pm 5$ \\
\hline Student $t$ & $* * \bar{*}$ & $* * *$ & $* * *$ & 0 & $* * *$ & $* * \bar{*}$ \\
\hline
\end{tabular}

***: $P<0.01 ; 0$ : not significantly different.

In experimental investigations, including biochemical and morphological analysis in rats, it is common to consider the gubernaculum as identical to the inguinal cone and to exclude the adhering ligament from further consideration (Raynaud, 1958; Hutson \& Donahue, 1986; George \& Peterson, 1988; George, 1989; Husmann \& McPhaul, 1991). This is the view adopted in the present study (see Figs 1-6 for support).

The study reveals that androgens contribute only to a minor extent, if at all, to the prenatal growth and perinatal inversion of the gubernacula. Gubernacular growth in male rats is unaffected by prenatal exposure to the potent anti-androgen flutamide. Gubernacular growth and differentiation between mesenchymatous core and muscular circumference proceeds normally, despite antiandrogens. Such findings have also been reported in rats exposed prenatally to the anti-androgen cyproterone acetate (Elger, 1966; Habenicht \& Neumann, 1983).

In contrast to the normal development of the gubernacula, typically androgen-dependent organs were all greatly affected by exposure to flutamide. Penile muscles, a penile urethra, bulbourethral glands and prostate failed to form, and vagina, nipples and underlying mammary-gland ducts developed. There was a variable, but incomplete, suppression of the development of the Wolffian duct derivatives in most of the rats, which may have resulted from their exposure to high local concentrations of androgens produced by the ipsilateral testis; anti-androgens may not reach these tissues in sufficiently high concentrations to counteract these androgens (Elger et al., 1970; Jost, 1971/72). This explanation for failure of complete suppression seems more plausible than 


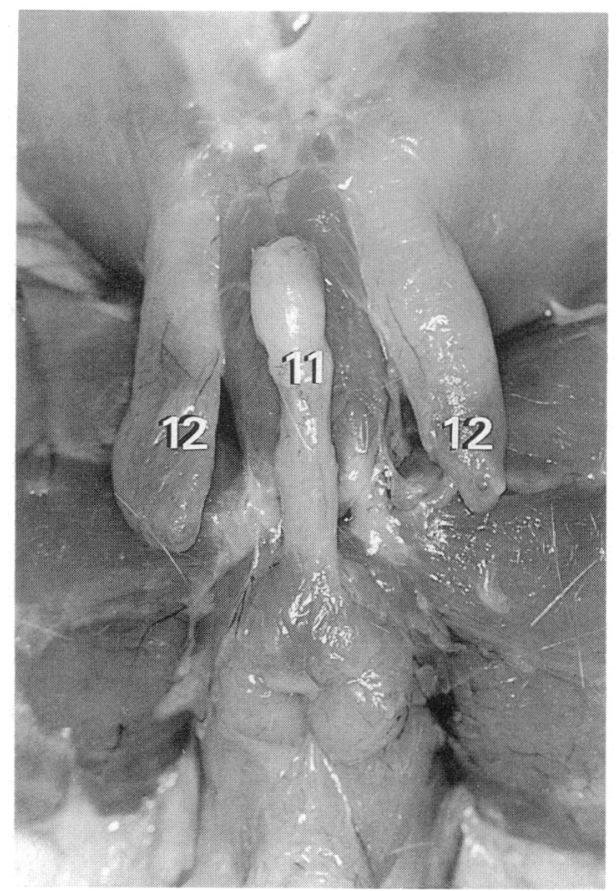

Fig. 6. The cremaster muscle sacs of a 1-year-old neonatally castrated rat that had not received any hormone treatment before 300 days of age; $\times 25$. The skin has been removed allowing the view of the penis (11) and the well-developed, empty scrotal sacs (12).

insufficient availability of, for example, $5 \alpha$-reduced androgens to the tissues as the result of exposure to flutamide. Male external genitalia do, indeed, require $5 \alpha$-reduced androgens for their development and internal genitalia do not (Wilson et al., 1981). However, there is no evidence that flutamide inhibits $5 \alpha$-reductase activity (Peets et al., 1974).

The female gubernaculum is much smaller than that of normal males and flutamide-exposed males. Exposure of females to flutamide did not result in gubernacular growth. The small size of the female gubernaculum could be due to either active suppression of its anlage through ovarian secretions or failure to grow as a result of the absence of growth-promoting testicular secretions (Moffat, 1987). Gubernacular growth in females is not enhanced through exposure to androgens during fetal life (Elger et al., 1970). Female gubernacular size at birth may represent 'unstimulated size' of these organs. The implication is that prenatal testes secrete homone(s) responsible for gubernacular growth.

Prenatal exposure to flutamide seemed to affect the onset of the perinatal inversion of the gubernacula. While inversion had started on the day of birth in control animals, there was no sign of its initiation in flutamide-exposed male animals. In contrast, the organs were large at birth. Absence of androgen action may have delayed inversion, but did not prevent it; intact rats, exposed prenatally to flutamide, showed gubernacular inversion between days 5 and 14 of postnatal life (P. van der Schoot, unpublished observations).

In rats castrated immediately after birth, to eliminate postnatal testicular hormone secretion including the immediate postnatal rise (Corbier et al., 1978), gubernacular inversion proceeded, seemingly unaffected, confirming the results with unilateral castration at birth by Bergh et al. (1978). On day 7, there were empty 'canals' attached to the lower abdomen, which had grown from the inverted gubernacula. Progress of inversion in control animals, which had started on the day of birth as revealed in the previous experiment, apparently did not require testicular hormonal action. 
Surprisingly, these 'canals' were also present, and properly developed and directed, in rats that had been exposed to flutamide from day 10 after conception to the day of birth. In these animals, gubernacula had not yet started inversion at the time of castration as established in the first experiment. The data demonstrate that the absence of androgen action before and after birth allows growth and inversion of the gubernacula.

Delay of gubernacular inversion in intact, flutamide-exposed male rats thus appears to depend on the presence of testes. It is difficult to think of testicular agents that inhibit the normal occurrence of gubernacular inversion, an event required for testicular descent. One could envisage a mechanical, rather than a hormonal, factor, reactivating a traditional view that testis descent in general, and growth of the cremaster muscle sac specifically, involves hormonal and non-hormonal factors (Selye, 1943; Frey et al., 1983).

Physical or mechanical differences between ovaries and testes are unlikely, on their own, to account for the whole of the male-specific gubernacular development and cremaster muscle growth. The gubernacula (or the later-developed cremaster muscles) have a specific motor innervation. Motoneurons in a part of the lumbar spinal cord $(\mathrm{L} 1 / 2 / 3)$ send their axons via the genitofemoral nerve to end on the cremaster muscle cells. Sex differences have been reported in the lumbar motoneuronal architecture (Kojima et al., 1983; Kojima \& Sano, 1984). The precise development and relationship between this sex-specific motoneuronal architecture and growth and development of the cremaster muscles needs to be elucidated.

Testosterone administration after neonatal castration did not induce weight increase of the inverted gubernacula after birth: neonatally castrated rats showed no further enlargement by either TP treatment in infancy or TP treatment between days 33 and 55. Treatment of intact infant rats with DHTP affected internal and external genital development, as expected, but produced no cremaster muscle growth. Failure of either TP, in castrated rats, or DHTP, in intact rats, to induce cremaster muscle growth shows that these muscles are not a specific target for androgens. This conclusion is at variance with old data on this subject, which suggested that androgens had a stimulatory action on these muscles. Almquist \& Andrews (1944) showed that castration of adult rats resulted in significant weight reduction of the cremaster muscles. The administration of extremely large doses of TP for 3 weeks could maintain cremaster muscle weight at precastration values. The same large dose promoted cremaster muscle growth in prepubertally castrated rats. It is difficult to evaluate critically the significance of these findings, especially in view of the fact that mechanical stimuli of the cremaster muscles after castration, through insertion of a hormonally inert artificial glass testis, was also effective in preventing 'scrotal involution in adult castrates' (Selye, 1943). Failure of growth with androgens is consistent with the recent demonstration that the cremaster muscles of infant rats do not show androgen receptors (George \& Peterson, 1988; Husmann \& McPhaul, 1991). Failure of weight increase with TP or DHTP treatment demonstrates that an insufficient amount of $5 \alpha$-steroid reductase (George, 1989) in these muscles does not explain the result.

All the results provide compelling evidence that androgens play no role in the prenatal growth or the postnatal inversion and further development of the gubernacula and cremaster muscles. The results are in line with inguinal hernia sacs as a normal accompaniment of the testicular feminization syndrome in man and other animals. The results are also consistent with the normal occurrence of inguinal hernia sacs in boys with cryptorchidism in whom testes have remained in an intra-abdominal position. Failure of testis descent does not include failure of the formation of the muscular cavities into which the testes are to descend (Hutson et al., 1990).

If androgens play no role in gubernacular growth or formation of the cremaster muscles, there must be another testicular hormone involved in gubernacular growth. There have been speculations that anti-Müllerian hormone $(\mathrm{AMH})$, rather than androgens, could be the hormone involved in testicular descent, but a role for AMH in cremaster muscle formation is unlikely. The clinical syndrome of persistent Müllerian duct in boys, resulting from absence of AMH production or secretion of a defective AMH molecule, is associated with the presence of inguinal hernia sacs 
(Sheehan et al., 1985; Hutson \& Donahue, 1986). In transgenic mice showing abnormally high AMH expression, affected males showed genital feminization and cryptorchidism, not just indicative of enhanced cremaster muscle growth associated with enhanced AMH expression (Behringer $e t$ al., 1990).

A further possible mechanism could be that cremaster sac formation results from the direct expression of a gene on the $\mathrm{Y}$ chromosome. Cremaster sac development does not require an intact $\mathrm{Y}$ chromosome, as indicated by the presence of cremaster sac in XX sex-reversed mice (Chubb \& Nolan, 1984) and XX men (de la Chapelle, 1972). Indirect support for a role of the Y chromosome comes from the finding of inguinal herniae without normal testicular or ovarian tissues in freemartin pigs with XX and XY cell lines (Colenbrander \& Wensing, 1975). However, absence of inguinal herniae in cattle freemartins does not support such a view (Jost et al., 1973). Also, human individuals affected by the syndrome of XY gonadal agenesis do not develop cremaster muscles, despite the presence of a Y chromosome (Polani, 1962; Kadotani et al., 1971; Sarto \& Opitz, 1973).

An ovarian factor could be involved, acting to reduce gubernacular size. Gubernacula in male and female rats are the same size on day 14 after conception. Further development can be interpreted as atrophy in females rather than growth in males (Radhakrishnan et al., 1979). Such a hypothesis is, however, difficult to reconcile with the idea that ovarian hormonal secretions do not play a critical role in prenatal sexual differentiation (Jost, 1972; George et al., 1981). Moreover, the human XO Turner syndrome provides an example of individuals who have never had hormonally functional gonads, and these individuals do not show a male-type gubernaculum or postnatal cremaster muscle development.

One last point deserves further attention: the normal occurrence of the plexus pampiniformis after prenatal exposure to flutamide. The plexus pampiniformis is the male-specific vasculature of the testis and is required for keeping the testicular temperature below body core level. Testis hormones during fetal life seem the logical organizers of the vascular pattern. The normal development of this vascular pattern, despite exposure to flutamide, indicates that testis hormones other than androgens are the factors involved. Alternatively, its presence in flutamide-exposed rats could indicate that local androgens, which can only be suppressed incompletely in their actions through systemically administered anti-androgens, are the organizers of the vascular pattern.

I thank I. Tabachnick (Schering Ltd, Bloomfield, NJ) for providing the samples of flutamide and C. Wensing (Central Veterinary Institute, Lelystad, Netherlands) for helpful advice on problems of normal and abnormal testicular descent.

Thanks are due to the enthusiastic cooperation of $A$. van Deurzen in preparing and studying the histological preparations of neonatally castrated and hormone-treated male animals as part of a laboratory stage in the programme of the Reynevelt College (Delft, Netherlands); P. van der Vaart was helpful in providing all other histological sections and the micrographs.

\section{References}

Almquist, J.O. \& Andrews, F.N. (1944) Effect of testosterone propionate on thermoregulatory function of rat scrotum. Anatomical Record 89, 125-133.

Beasley, S.W. \& Hutson, J.M. (1988) The role of the gubernaculum in testicular descent. Journal of Urology 140, 1191-1193.

Behringer, R.R., Cate, R.L., Froelick, G.J., Palmiter, R.D. \& Brinster, R.L. (1990) Abnormal sexual development in transgenic mice chronically expressing Müllerian inhibiting substance. Nature 345, 167-170.

Bergh, A., Helander, H.F. \& Wahlqvist, L. (1978) Studies on factors governing testicular descent in the rat-particularly the role of gubernaculum testis. International Journal of Andrology 1, 342-356.
Campbell, M.F. (1970) Anomalies of the genital tract. In Urology, 3rd edn, pp. 1573-1670. Eds M. F. Campbell \& J. H. Harrison. Saunders, Philadelphia.

Chapelle, A. de la (1972) Nature and orgin of males with $\mathrm{XX}$ sex chromosomes. American Journal of Human Genetics 24, 71-105

Chubb, C. \& Nolan, C. (1984) Leydig cell function in the absence of an intact $\mathrm{Y}$ chromosome. Biology of Reproduction 31, 536-540.

Colenbrander, B. \& Wensing, C.J.G. (1975) Studies of phenotypically female pigs with hernia inguinalis and ovarian aplasia. Proceedings Koninklijke Nederlandse Academie voor Wetenschappen C78, 33-42. 
Corbier, P., Kerdelhué, B., Picon, R. \& Roffi, J. (1978) Changes in testicular weight and serum gonadotropin and testosterone levels before, during and after birth in the perinatal rat. Endocrinology 103, 1985-1991.

Elder, J.S., Isaacs, J.T. \& Walsh, P.C. (1982) Androgenic sensitivity of the gubernaculum testis: evidence for hormonal/mechanical interactions in testicular descent. Journal of Urology 127, 170-176.

Elger, W. (1966) Die Rolle der fetalen Androgene in der Sexualdifferenzierung des Kaninchens und ihre Abgrenzung gegen andere hormonale und somatische Faktoren durch Anwendung eines starken Antiandrogens. Archives d'Anatomie microscopique et de Morphologie expérimentale 55, 658-743.

Elger, W., Steinbeck, H., Cupceancu, B. \& Neumann, F. (1970) Influence of methyltestosterone and cyproterone acetate on Wolffian duct differentiation in female rat foetuses. Journal of Endocrinology 47, $417-422$.

Feigelson, M. (1986) Suppression of testicular maturation and fertility following androgen administration to neonatal male rats. Biology of Reproduction 35, 1321-1332.

Fentener van Vlissingen, J.M., Blankenstein, M.A., Thijssen, J.H.H., Colenbrander, B., Verbruggen, A.J.E.P. \& Wensing, C.J.G. (1988) Familial male pseudohermaphroditism and testicular descent in the racoon dog (Nyctereutes). Anatomical Record 222, 350-356.

Frey, H.L., Peng, S. \& Rajfer, J. (1983) Synergy of abdominal pressure and androgens in testicular descent. Biology of Reproduction 29, 1233-1239.

George, F. (1989) Developmental pattern of $5 \alpha$-reductase activity in the rat gubernaculum. Endocrinology 124, 727-732.

George, F. \& Peterson, K.G. (1988) Partial characterization of the androgen receptor of the newborn rat gubernaculum. Biology of Reproduction 39, 536-539.

George, F.W., Griffin, J.E., Leshin, M. \& Wilson, J.D. (1981) Endocrine control of sexual differentiation in the human. In Fetal Endocrinology, pp. 341-357. Eds M. J. Novy \& J. A. Resko. Academic Press, New York.

Habenicht, U. \& Neumann, F. (1983) Hormonal regulation of testis descent. In Advances in Anatomy, Embryology, and Cell Biology Vol. 81, pp. 1-55. Springer, Berlin.

Hamilton, J.B. (1938) The effect of male hormone upon the descent of the testis. Anatomical Record 70, 533-541.

Hamilton, W.J., Boyd, J.D. \& Mossman, H.W. (1962) Human Embryology, 3rd edn, Heffer, Cambridge.

Husmann, D.A. \& McPhaul, M.J. (1991) Localization of the androgen receptor in the developing rat gubernaculum. Endocrinology 128, 383-387.

Hutson, J.M. (1986) Testicular feminization: a model for testicular descent in mice and men. Journal of Pediatric Surgery 21, 195-198.

Hutson, J.M. \& Donahue, P.K. (1986) The hormonal control of testicular descent. Endocrine Review's 7, $270-283$.

Hutson, J.M., Williams, M.P.L., Attah, A., Larkins, S. \& Fallat, M. (1990) Undescended testes remain a dilemma despite recent advances in research. Australia and New Zealand Journal of Surgery 60, 429-439.
Jones, H.W. \& Klingensmith, G.J. (1985) Congenital adrenal hyperplasia. In Clinical Reproductive Endocrinology, pp. 362-397. Ed. R. P. Shearman. Churchill Livingstone, Edinburgh.

Jost, A. (1971/72) Use of androgen antagonists and antiandrogens in studies on sex differentiation. Gynecological Investigations 2, 180-201.

Jost, A. (1972) A new look at the mechanisms controlling sex differentiation in mammals. Johns Hopkins Medical Journal 130, 38-53.

Jost, A., Vigier, B., Prepin, J. \& Perchellet, J.P. (1973) Studies on sex differentiation in mammals. Recent Progress in Hormone Research 29, 1-41.

Kadotani, T., Ohama, K., Sofuni, T. \& Ikeda, T. (1971) An XY human female with ovaries. American Journal of Obstetrics and Gynecology 110, 98-102.

Kirk, R.E. (1968) Experimental Design: Procedures for the Behavioral Sciences, Brooks/Cole, Belmont.

Kojima, M. \& Sano, Y. (1984) Sexual differences in the topographical distribution of serotonergic fibers in the anterior column of rat lumbar spinal cord. Anatomy and Embryology 170, 117-121.

Kojima, M., Takeuchi, Y. \& Kawata, M. (1983) Motoneurons innervating the cremaster muscle of the rat are characteristically densely innervated by serotoninergic fibers as revealed by combined immunohistochemistry and retrograde fluorescence DAPI-labeling. Anatomy and Embryology 168, 41-49.

Moffat, D.B. (1987) Lecture Notes on Anatomy. Blackwell Scientific Publications, Oxford.

Neri, R., Florance, K., Koziol, P. \& VanCleave, S. (1972) A biological profile of a nonsteroidal antiandrogen, SCH 13521 (4'-nitro-3'-trifluoromethylisobutyranilide). Endocrinology 91, 427-437.

Newton, B.W. \& Hamill, R.W. (1989) Target regulation of the serotonin and substance $P$ innervation of the sexually dimorphic cremaster nucleus. Brain Research 485, 149-156.

Peets, E.A., Henson, M.F. \& Neri, R. (1974) On the mechanism of the anti-androgenic action of flutamide $(\alpha-\alpha-$ $a$-trifluoro-2-methyl-4-nitro- $m$-propionotoluidide) in the rat. Endocrinology 94, 532-540.

Polani, P.E. (1962) Sex chromosome anomalies in man. In Chromosomes in Medicine, pp. 73-139. Ed. J. L. Hamerton, Heineman, London.

Polani, P.E. (1970) Hormonal and clinical aspects of hermaphroditism and the testicular feminizing syndrome in man. Philosophical Transactions of the Royal Society B 259, 187-204.

Pfeiffer, C.A. (1936) Sexual differences of the hypophyses and their determination by the gonads. American Journal of Anatomy 58, 195-225.

Radhakrishnan, J., Morikawa, Y., Donahue, P.K. \& Hendren, W.H. (1979) Observations on the gubernaculum during descent of the testis. Investigations in Urology 16, 365-368.

Raynaud, A. (1958) Inhibition, sour l'effet d'une hormone oestrogène, du développement du gubernaculum du foetus mâle de Souris. Comptes Rendus Academie Science (Paris) 246, 176-179.

Rosenfield, R.L., Lawrence, A.M., Liao, S. \& Landau, R.L. (197I) Androgens and androgen responsiveness in the feminizing testis syndrome. Comparison of 
complete and 'incomplete' forms. Journal of Clinical Endocrinology 32, 625 632.

Sarto, G.E. \& Opitz, J.M. (1973) The XY gonadal agenesis syndrome. Journal of Medical Genetics 10 , 288-293.

Scheffer, I.E., Hutson, J.M., Warne, G.L. \& Ennis, G. (1988) Extreme virilization in patients with congenital adrenal hyperplasia fails to induce descent of the ovary. Pediatric Surgery International 3, 165-168.

Selye, H. (1943) Factors influencing development of the scrotum. Anatomical Record 85, 377-385.

Sheehan, S.J., Tobbia, I.N., Ismail, M.A., Kelly, D.G. \& Duff, F.A. (1985) Persistent Müllerian duct syndrome: review and report of 3 cases. British Journal of Urology 57, 548-551.

Siegel, S. (1956) Non-parametric Statistics. McGraw-Hill, Kogakusha.

Stanley, A.J., Gumbeck, L.G. \& Allison, J.E. (1973) Male pseudohermaphroditism in the laboratory Norway rat. Recent Progress in Hormone Research 29, 43-64.

Starck, D. (1965) Embryologie. Thieme Verlag, Stuttgart.
Welschen, R., Osman, P., Dullaart, J., de Greef, W.J., Uilenbroek, J.Th.J. \& de Jong, F.H. (1975) Levels of follicle-stimulating hormone, luteinizing hormone, oestradiol-17 $\beta$ and progesterone, and follicular growth in the pseudopregnant. Journal of Endocrinology 64, 3447.

Wensing, C.J.G. (1986) Testicular descent in the rat and a comparison of this process in the rat with that in the pig. Anatomical Record 214, 154-160.

Wensing, C.J.G. \& Colenbrander, B. (1986) Normal and abnormal testicular descent. Oxford Reviews of Reproductive Biology 8, 130-164.

Wilson, J.G. \& Wilson, H.C. (1943) Reproductive capacity in adult male rats treated prepuberally with androgenic hormone. Endocrinology 33, 353-360.

Wilson, J.D., Griffin, J.E., George, F.W. \& Leshin, M. (1981) The role of gonadal steroids in sexual differentiation. Recent Progress in Hormone Research 37, $1-39$.

Received 15 February 1991 